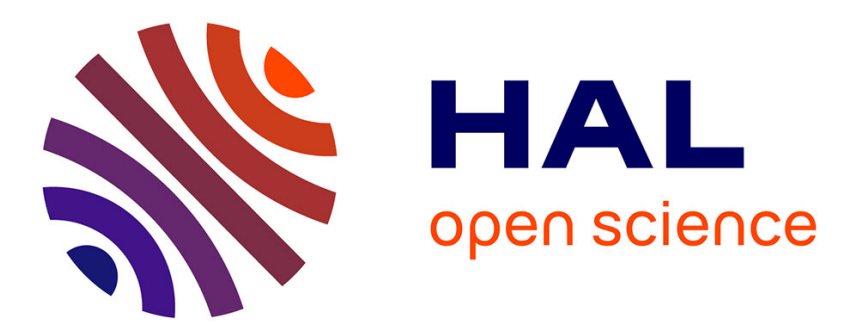

\title{
Design of Multi-Beam Nonagon Fractal Array for Satellite Applications
}

V a Sankar Ponnapalli, Venkata a Sankar Ponnapalli, Jayasree Pappu, V.y Jayasree Pappu

\section{- To cite this version:}

V a Sankar Ponnapalli, Venkata a Sankar Ponnapalli, Jayasree Pappu, V.y Jayasree Pappu. Design of Multi-Beam Nonagon Fractal Array for Satellite Applications. SREYAS International Journal of Scientists and Technocrats, 2017, 1 (3), pp.33 - 36. 10.24951/sreyasijst.org/2017031005 . hal01664585

\section{HAL Id: hal-01664585 \\ https://hal.science/hal-01664585}

Submitted on 15 Dec 2017

HAL is a multi-disciplinary open access archive for the deposit and dissemination of scientific research documents, whether they are published or not. The documents may come from teaching and research institutions in France or abroad, or from public or private research centers.
L'archive ouverte pluridisciplinaire HAL, est destinée au dépôt et à la diffusion de documents scientifiques de niveau recherche, publiés ou non, émanant des établissements d'enseignement et de recherche français ou étrangers, des laboratoires publics ou privés. 


\title{
Design of Multi-Beam Nonagon Fractal Array for Satellite Applications
}

\author{
"Venkata A Sankar Ponnapalli", V.Y Jayasree Pappu ${ }^{2}$ \\ ${ }^{1}$ Department of Electronics and Communication Engineering, Sreyas Institute of Engineering \\ and Technology, Hyderabad-500068, India. \\ ${ }^{2}$ Department of Electronics and Communication Engineering, GITAM University, \\ Visakhapatnam-530045, India.
}

Received: 12 December 2016, Revised: 7February 2017, Accepted: 25 February 2017, Published: 28 February 2017

\begin{abstract}
Fractal array antenna design process depends on the repetitive geometric design methodology. Owing to this reason, these antennas are also named as artistic antennas. This research paper proposed a nonagon fractal array antenna designed using concentric elliptical ring sub array geometric generator for satellite and other advanced wireless based communication systems. The proposed nonagon fractal array have designed up to four iterations and for two different expansion levels. Owing to the recursive nature of fractal structures proposed are array exhibits multi-beam behaviour with fine array factor characteristics. The proposed nonagon fractal arrays are analyzed and simulated by MATLAB 15 programming.
\end{abstract}

Keywords: Fractal, Nonagon fractal array, Array factor, Expansion level, Iteration.

\section{INTRODUCTION}

Array antennas have been used to accomplish less side lobe ration and fine directivity requisites in wireless based advanced communication systems and satellite communication [1-3]. Fractal Arrays (FAs) have been used to realize the multi-beam, wide band and ultra wide band applications in satellite, celestial, and other advanced wireless communication systems [4, 5]. Basically FAs are geometry-based not material-based. Owing to this reason they are also known as artistic arrays. FAs are again classified into two basic types based on their geometrical construction. They are random and deterministic FAs [6-8]. Concentric circular ring sub array geometric generator is one of the pioneer deterministic fractal geometry for the generation and design of linear and planar FAs. Cantor linear FA of odd and even number of antenna elements, square, triangular, pentagonal, hexagonal, heptagonal, octagonal and Sierpinski triangle and square FAs are designed using this repetitive methodology [9-11].
Ahead of this repetitive geometric methodology, other categories of FAs also existed. They are nature inspired random FAs [12]. The Cantor ring array is also the best example for FAs. These arrays are generated by polyadic Cantor set and designed for less side lobe ratios with less number of antenna elements [13]. A big challenge in the design of FAs after large number of antenna elements is gaps and overlaps between the antenna elements. To avoid this problem, fractile arrays are introduced by D.H. Werner et al. [14]. Dragon, flap, and twig FAs are proposed by Ahmed et al. [15], to accomplish the requisites like abated side lobe ratios and wider side lobe angle for satellite communication systems. Concentric Elliptical ring Sub-array geometric Generator (CESG) for the design of deterministic FAs has been proposed for multi-beam radiation and for better array factor properties [16-19]. This research paper proposed a nonagon (nine antenna elements) FA using CESG design methodology with uniform current excitations.

*Corresponding Author. Tel.: +918125550684

Email address: vadityasankar@gmail.com(V.A.S.Ponnapalli)

https://dx.doi.org/10.24951/sreyasijst.org/2017031005

Double blind peer review under responsibility of Sreyas Publications

2456-8783@ 2017 Sreyas Publications by Sreyas Institute of Engineering and Technology. This is an open access

article under the CC BY-NC-ND license (http://creativecommons.org/licenses/by-nc-nd/4.0/) 
Section 2 of this research article explains CESG design methodology and introduces design equations of nonagon FA. Section 3 of this research article deals with the results and the discussion of the proposed nonagon FA. Section 4 of this article draws the conclusion and future research work.

\section{DESIGN EQUATIONS OF NONAGON FRACTAL ARRAY}

Actually, the repetitive geometric designs and design methodologies are helpful for the improvement of array factor behaviour of FAs. This research article proposes a nonagon FA for an expansion level (E) of two and for four iterations (I), using CESG design methodology, as shown in Figure 1 and Figure 2. CESG methodology is the same as the concentric circular ring sub array geometric generator; but, in this case the circular sub-array generator is substituted with elliptical subarray generator. The radius is the significant parameter in the concentric circular sub array generator; but, eccentricity is the significant consideration in the CESG design methodology. Eccentricity of the sub-array generator will be varied using major axis (a) and minor axis (b). Generating array factor of basic CESG design methodology is expressed in (2.1) and resulting array factor is defined in (2.2). Actually FAs can be generated up to infinite extend; but, in this case up to four iterations (I) have been considered.
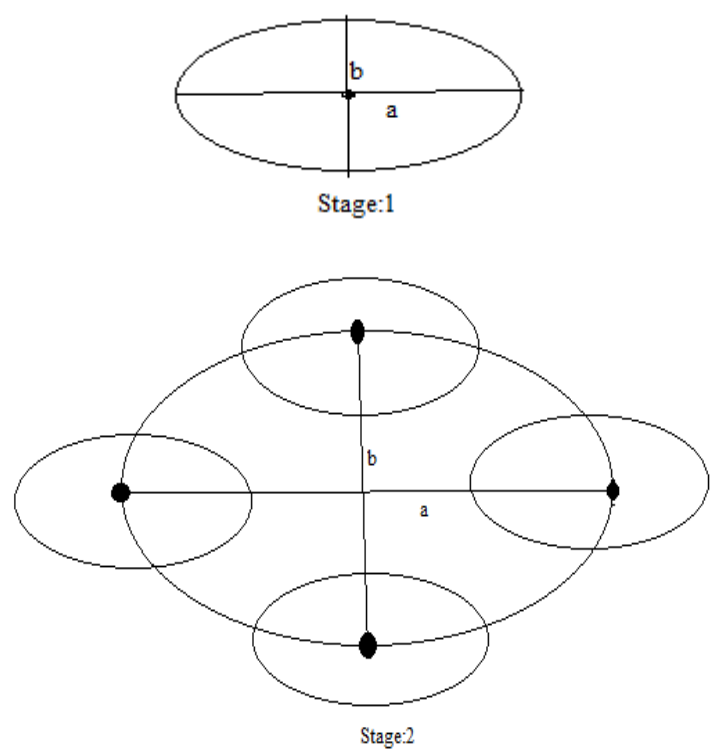

Figure 1.CESG methodology for stage: 1 and stage:2

$$
\operatorname{GA}(\theta, \phi)=\sum_{m=1}^{\mathrm{M}} \sum_{\mathrm{n}=1}^{\mathrm{N}} \mathrm{A}_{\mathrm{mn}} \mathrm{e}^{\mathrm{jk} \psi_{\mathrm{mn}}}
$$

A. $\mathrm{F}_{\mathrm{P}}(\theta, \phi)=\prod_{\mathrm{I}=1}^{\mathrm{I}}\left[\sum_{\mathrm{m}=1}^{\mathrm{M}} \sum_{\mathrm{n}=1}^{\mathrm{N}} \mathrm{A}_{\mathrm{mn}} \mathrm{e}^{\mathrm{jkE} \mathrm{E}^{\mathrm{I}-1} \Psi_{\mathrm{mn}}}\right]$

The array factor of nonagon FA for an expansion factor of two with four successive iterations is expressed in (2.3).

A. $\mathrm{F}_{\mathrm{P}}(\theta, \phi)=\prod_{\mathrm{I}=1}^{4}\left[\sum_{\mathrm{m}=1}^{1} \sum_{\mathrm{n}=1}^{2} \mathrm{~A}_{\mathrm{mn}} \mathrm{e}^{\mathrm{jk} 2^{\mathrm{I}-1} \psi_{\mathrm{mn}}}\right]$

$\Psi_{\mathrm{mn}}=\sin \theta\left(\mathrm{a} \cos \phi_{\mathrm{n}} \cos \phi+\mathrm{b} \sin \phi_{\mathrm{n}} \sin \phi\right)-$

$\sin \theta_{0}\left(\operatorname{acos} \phi_{\mathrm{n}} \cos \phi_{0}+\mathrm{bsin} \phi_{\mathrm{n}} \sin \phi_{0}\right)$

where $I$ is the iteration levels in (2.4). In this research article, up to four iterations have been considered, to generate the proposed array. E is the expansion level. A is the current amplitudes, $\mathrm{k}$ is the wave equation, $m$ indicates the number of concentric rings and $\mathrm{n}$ indicates the number of antenna elements for each iteration.

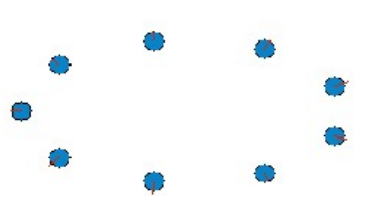

Stage: 1

Figure 2.First iteration of nonagon (nine elements) FA

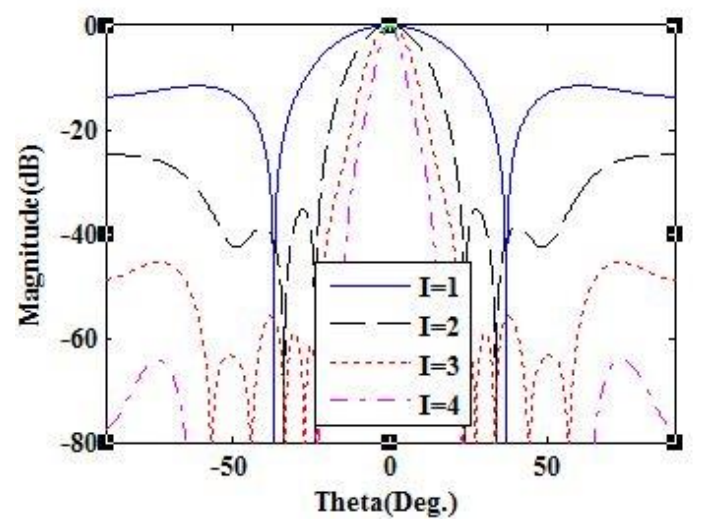

Figure 3.Array factor behavior of nonagon FA for four successive iterations

Table 1.Array factor properties of nonagon FA for expansion level of two with four successive iterations

\begin{tabular}{|l|l|l|l|}
\hline Ite.(I) & $\begin{array}{l}\text { HPBW } \\
(\mathrm{o})\end{array}$ & $\begin{array}{l}\text { SLL } \\
(\mathrm{dB})\end{array}$ & $\begin{array}{l}\text { S.A. } \\
(\mathrm{o})\end{array}$ \\
\hline 1 & 31.4 & -11.6 & 57.6 \\
\hline 2 & 16.4 & -35.3 & 27.5 \\
\hline 3 & 25.2 & -61.3 & 9.4 \\
\hline 4 & 5.4 & -82.3 & 7.6 \\
\hline
\end{tabular}

*Ite.- Iterations, HPBW- Half Power Beam Width, SLL- Side lobe level, S.A.- Side lobe level angle. 


\section{RESULTS AND DISCUSSION}

This research article focuses on the design of nonagon FA using CESG. Here the basic array starts with nine elements and it can extend up to infinite iterations. But, this paper considered up to four successive iterations for expansion factors of two. Figure 3 exemplifies that, while increasing the iterations of nonagon FA, there is a concurrent decrease observed in the beam width. All array factor values are tabulated in the Table 1 .

\section{CONCLUSION}

The proposed nonagon FA shows better performance in all the array factor properties and these array factors are more suitable for satellite and other advanced wireless systems owing to the narrow beam of $5.4^{0}$ with -82.3 side lobe ration at the forth iteration.

\section{REFERENCES}

[1] M.T.Ma, Theory and application of Antenna Arrays, John Wiley \& Sons, USA, 1974.

[2] C.A.Balanis and A.C.Polycarpou, Analysis and Design, John Wiley \& Sons, Inc., Publication, New Jersey, 1997.

[3] R.J.Mailloux, Phased Array Antenna Handbook, Second Edition, Artech House, 2005, pp. 1-689.

[4] D.H.Werner and R.Mittra, Frontiers in Electromagnetics, IEEE Press, 2000. http://dx.doi.org/10.1109/MAP.2001.951563.

[5] J.Anguera, C.Puente and C.Borja, Fractal shaped Antennas: A review, Encyclopedia of RF and Microwave Engineering, 2005, pp.1620-1635,

http://dx.doi.org/10.1002/0471654507.eme128.

[6] Constantine A.Balanis and Steven R.Best, Small and Fractal Antennas, Modern Antenna Handbook, John Wiley \& Sons, Inc., http://dx.doi.org/10.1002/9780470294154.ch10.

[7] D.H.Werner and S.Ganguly, An Overview of Fractal Antenna Engineering Research, IEEE Transactions on Antennas and Propagation Magazine, Vol. 45, No. 1, 2003, pp. 38-57.

[8] V.A.S.Ponnapalli and P.V.Y.Jayasree, Heptagonal Fractal Antenna Array for Wireless Communications, Electromagnetics and Telecommunica- tions, Lecture notes in Electrical Engineering, Vol. 372, 2016, pp. 387394, http://dx.doi.org/10.1007/978-81-3222728-1 34.
[9] D.H.Werner, R.L.Haupt and P.L.Werner, Fractal Antenna Engineering: The theory and design of Antenna Arrays, IEEE Transactions on Antennas and Propagation Magazine, Vol. 41, No. 5, 1999, pp.37-59, http://dx.doi.org/10.1109/74.801513.

[10] Waroth Kuhirun, A new design methodology for Modular Broadband Arrays based on Fractal Tilings, Thesis in Electrical Engineering, The Pennsylvania State University, 2003.

[11] V.Srinivasa Rao and V.A.Sankar Ponnapalli, Study and analysis of Fractal Linear Antenna Arrays, IOSR-JECE, Vol. 5, No. 2, 2013, pp. 23-27.

[12] Y.Kim and D.L.Jaggard, The Fractal Random Array, Proceedings of the IEEE Conference, Vol. 74, No. 9, 1986, pp.1278-1280. http://dx.doi.org/10.1109/PROC.1986.13617.

[13] D.L.Jaggard and A.D.Jaggard, Cantor Ring Arrays, Antennas and Propagation Society International Symposium, IEEE, Vol. 2, 1998, pp. 866-869. http://dx.doi.org/10.1109/APS.1998.702076.

[14] D.H.Werner, Waroth Kuhirun and P.L.Werner, Fractile Arrays: A New Class of Tiled Arrays with Fractal Boundaries, IEEE Transactions on Antennas and Propagation Magazine, Vol. 52, No. 8, 2004, pp. 2008-2018, http://dx.doi.org/10.1109/TAP.2004.832327.

[15] Ahmed Najah Jabbar, New Elements Concentrated Planar Fractal Antenna Arrays for Celestial Surveillance and Wireless Communications, ETRI Journal, Vol. 33, No. 6, 2011, pp. 849-856. http://dx.doi.org/10.4218/etrij.11.0111.0036.

[16] V.A.Sankar Ponnapalli and P.V.Y.Jayasree, Novel design methodology for the generation of Deterministic Fractal Antenna Arrays, IEEE International Microwave and RF Conference, 2015, pp. 337-339.

[17] V.A.Sankar Ponnapalli and P.V.Y.Jayasree, Design of Multi-beam Rhombus Fractal Array Antenna using new Geometric design methodology, Progress in Electromagnetics Research C, Vol. 64, 2016, pp. 151-158, http://dx.doi.org/10.2528/PIERC16031202.

[18] V.A.Sankar Ponnapalli and P.V.Y.Jayasree, Design and Analysis of Novel Fractal Linear and Planar Array Antennas for Satellite Applications, Advanced Electromagnetics 
Journal, Vol. 5, No. 3, 2016, pp. 56-62, http://dx.doi.org/10.7716/aem.v5i3.400.

[19] T.Aseer Brabin and S.Ananth, Analysis of Overall Heat Transfer Coefficient and Effectiveness in Split Flow Heat Exchanger using Nano Fluids, Journal of Advances in Mechanical Engineering and Science, Vol. 1, Vol. 3, 2015, pp. 28-40, http://dx.doi.org/10.18831/james.in/201503100 $\underline{4}$. 